\title{
EDUCATION
}

\section{ELEMENTS THAT CONTRIBUTE TO THE EFFICIENCY OF COMMUNICATION BETWEEN TEACHER AND STUDENT}

Marinela Rusu ${ }^{247}$

\begin{abstract}
Communication skills are one of the most important educational elements today. Current education has already included communication competencies as independent objectives in the education of young generations. Communication is a multidisciplinary existential basis and that is why its understanding is not easy, and must be approached scientifically, conceptually and structurally. This paper aims to emphasize the importance of communication in the teaching-learning process and its direct correlation with school success but also with success in life. Teachers need communication more than anyone. Their verbal communication occupies $70 \%$ of a class lesson (Haslett, 1987). The appeal to the elements of emotional intelligence, to the motivation / interests of the students, becomes a necessity and at the same time they are constituted as factors that can improve and make efficient the didactic communication. In this paper we will analyze the main functions of teacher-student communication (guidance, information and thought challenge). There are described other elements that can also contribute to better communication in the classroom: active presentation of topics, providing summaries, resumption of main ideas, clarity of presentation (sentence logic, examples and explanations), assessment of comprehension deficiencies and their correction, frequently asked questions. All these aspects have proved, through the studies carried out, that they are positively correlated with the students' results.

The verbal communication of the educator is always accompanied by the elements of nonverbal communication that have an important role in achieving an effective instructiveeducational process. In this regard, we can mention a few essential components: posture, gestures, facial expressions, style of dressing, tone of voice, all of which can incite or divert the listener's attention. Another important element in effectiveness of the didactic communication is the knowledge of the cultural, economic and social environment from which the students come, their specific characteristics. The interaction will be more plausible, accessible to the student, when well known, culturally familiar aspects are inserted in the complex process of teacherstudent communication. The integration of cultural diversity in didactic communication has become a stringent requirement of modern education.
\end{abstract}

Key words: didactic communication, efficiency, competencies, non-verbal communication, cultural environment

\section{Interaction and communication in the educational process}

Communication is the key element of education, teaching and learning and, at the same time, it affects the individual throughout his life. Because communication is a multi-disciplinary and multi-dimensional concept it is connected to all sciences and has a multitude of definitions (Caliskan \& Karadag,

${ }^{247}$ Marinela Rusu, Researcher PhD. and visual artist, Romanian Academy, Institute "Gheorghe Zane" from Iași Branch, Romania, email: marinela1808@yahoo.com 
2009, D. E., Hewes, 1995). One of them states that communication is a process in which two or more people share the same significations (Yalin, 2001) and emphasizes that human existence is based on a transfer of information and the lack of communication will make life impossible (Heather et al., 1995). In education and more specifically, in the learning process, communication helps to determine changes in behaviors and expresses one's own ideas and thoughts, as well as ideas /thoughts that affect relationships with others. Today, the importance of communication is growing, as it is the fundamental tool of information transfer. The current era is marked by the creation of what is called cyberspace. Individuals can form common areas of communication (dialogue) through knowledge, technology and interaction. When the concepts of education, teaching and teacher are questioned (for reasons such as: culture, language, racial motives, economic differences, etc.), structuring common areas of communication becomes mandatory.

Communication is a necessity for all individuals. But among them, teachers are the ones who need communication more than anyone, as it becomes an obligation for them. In their interaction and communication with students, teachers should influence them in order to interact. Teachers should be democratic in their attitudes, tolerant, smiling, pleasant, patient and trustworthy. If they want to teach effectively in the teaching-learning process, they should interact appropriately, knowing the basic factors of communication.

\section{Non-verbal communication}

In addition to verbal language, nonverbal cues affect the meaning of communication. Hundreds of studies have been conducted in this area of communication (Heather et al, 1995, Burgoon, 1985). Lustig and Koester (1999) suggested that nonverbal communication serves to emphasize, complete, contradict, regulate, and replace verbal messages. We can use a nonverbal message to emphasize a point of view. At the same time, nonverbal messages can be contradictory. Think of the teacher looking at his watch as he says, "Come in and tell me; I always have time for my students." Nonverbal communication can be used to replace verbal messages. For example, a teacher might put a index finger over his mouth to ask for silence. These general functions of nonverbal communication become problematic when we introduce the culture factor. Students from different cultural backgrounds have different interpretations for nonverbal communication. White students "smile and nod" when they agree with a teacher, while Asian students may "smile and nod" when they do not understand the teacher. Knapp and Hall (1992) provided a useful typology for examining nonverbal communication in the classroom. Their classification consists of: (a) environmental /cultural factors, movement and (e) paralanguage.

(b) physical appearance, (c) proximity,

Teachers' behavior has an impact on students' attitudes. Much research has focused on the idea of proximity. According to Mehrabian's (1981) theory, closeness behaviors include: smile, eye contact, body dynamics, closeness and relaxed posture. A number of studies have shown that teachers who are often in 
close proximity to students are perceived positively, regardless of students' cultural identities (Collier \& Powell, 1990; Sanders \& Wiseman, 1990). Through such behavior, teachers indicate that they are open and like to interact and communicate with their students.

One of the most controversial non-verbal behaviors is one of an emotional nature. Touching, considered an essential component of human development, can be problematic in the classroom. Touch can be used to comfort, discipline and focus attention. When used properly, touch can send strong messages of affirmation and concern. However, improper touching can be devastating. Behaviors that seem appropriate in one situation can become contentious and controversial in another. Hugging a third grader who falls in the hallway during a break, may be appropriate, while hugging a student in an empty classroom because he is a good student may have a different implication. Mongeau and Blalock (1994) found that of all the proximity behaviors of the teachers they studied, touch is the only one perceived as inappropriate.

Paralanguage. Knapp and Hall (1992) note that language is always accompanied by nonlinguistic elements of speech, such as: voice volume, tempo, tone, intensity, and emitted sounds. The accent is also certainly a paralinguistic feature that influences classroom communication. Research shows that accent influences the speaker's credibility. Gill (1994) investigated the effects of accent on understanding. The results indicate that listeners had more favorable responses to teachers with standard North American accents than those with British or Malaysian accents. Moreover, students were able to understand more information from North American teachers than from foreign teachers.

Listening. Understanding the meanings transmitted is closely related to the ability to listen. Students who are distracted may not focus on main ideas or have difficulty following instructional messages. Wolvin and Coakley (1993) provided a useful typology of listening, consisting of five major functions.

- Discriminatory listening distinguishes between auditory and visual stimuli. This type of listening underlies all other forms of listening. Discriminatory ability is fundamental for musicians, car mechanics, parents and teachers. Everyone has to determine the meaning of certain sounds and how to respond to them.

- Listening for understanding (comprehension) is based on discriminating stimuli in relation to understanding the message. Much of the educational process involves this function of listening. Students listen to lectures, student reports, class discussions, teacher observations and reprimands. Successful understanding of messages requires that listeners avoid an evaluative attitude toward the topic being discussed or the speaker. Listening becomes difficult when the listener does not like the speaker.

- Therapeutic listening, states Wolvin and Coakley (1993), requires the listener to help the speaker solve problems. To perform this function, the listener becomes like an immersion platform so that the subject can identify and solve a problem. Teachers often play this role when they listen to the difficulties that students have at home or the conflicts they have with their classmates at school. In these contexts, the teacher tries to empathize with the speaker and show understanding. 
- Critical thinking requires the listener to make a judgment about the information received. Students must learn that criticizing an argument does not mean criticizing the person.

- Appreciative listening is the final function that Wolvin and Coakley (1993) discussed. This type of listening is subject to individual tastes and standards.

There are many circumstances that make it difficult to listen effectively. One of them is that listening has a subjective character, always being a part of an interpersonal relationship. Students' preferences (related to learning but also to the personality of teachers) directly influence the efficiency of a communication in the classroom. Therefore, in order to interact and communicate in the classroom, researcher Malcho (2000) has the opinion that the teacher have to:

to use explicit language and must control their language;

to analyze the students' way of thinking, starting from the bodily reactions and to use consciously the body language;

$>$ to annihilate the elements that distract the student's attention;

$>$ to have sufficient knowledge regarding teaching methods and techniques;

$>$ to know the tools and materials necessary for teaching and to use them in a professional manner.

$>$ to teach as in a game, aiming to facilitate and motivate learning;

$>$ to use the feedback mechanism in an efficient way and to evaluate the instantaneous feedback;

to always come and leave the class on time;

$>$ other stimulants (pleasant smells, wearing different clothes, etc.) should be applied.

The teacher is responsible for the efficient transmission of the message. So, it should know the attributes of its receptors and enrich the communication environment, by using several communication channels (Demirel, Seferoglu \& Yagci, 2002).

\section{The role of emotional intelligence (EI) in communication}

Goleman (1997) expanded Gardner's work on emotional skills. Individuals who are emotionally intelligent are able to regulate their emotional states. Today, there is a growing interest in the connection that can exist between the field of emotions and the complex process of communication and learning. As mentioned in his papers, Goleman (1997) described five dimensions of emotional intelligence:

Knowing one's emotions: recognizing a certain emotional state. The ability to monitor one's own emotions and feelings plays an important role in selfknowledge and the knowledge of others.

Emotion management: the ability to adequately overcome anxiety or sadness, being essential in guiding behavior towards success.

Motivation: when emotions act in the service of a goal, it will favor the development of the individual towards improvement and performance.

> Recognizing the emotions of others: also known as empathy, this ability has a social specificity par excellence. Understanding how other people feel in certain 
situations leads to better adaptation, to more effective collaboration and communication.

Relationship management: involves the ability to create positive relationships, to gain popularity, to become a leader; this ability will lead to much increased interpersonal efficiency.

In the classroom, emotional intelligence plays a particularly important role, as the way students manage their emotions directly influences the approach to academic tasks and their ability to work with other students. Healy (1998) argued that socio-emotional factors are important predictors of academic success and success in life. The researcher conducted a study that investigated the ability of preschoolers to delay the desire for immediate satisfaction. Preschoolers were given a cake and told that if they could wait 15-20 minutes, then they would receive two cakes. These students were re-evaluated 14 years later. The results showed that students who may delay the satisfaction of the momentary pleasure, had outstanding academic results, were much more liked by teachers and colleagues and showed greater emotional stability. Emotional intelligence has a significant role in the harmonious development of the personality, thus becoming capable of self-control and emotional self-regulation, capable of empathy for peers, capable of altruism and dedication to colleagues and friends. Encouraging students to work /learn before they start playing, to persevere in achieving their goals, despite their impediments, to be respectful and empathetic, helps to promote an attitude of involvement and efficiency: all this, in turn, will have a positive impact on the academic achievements of young people (Marinela Rusu, 2015).

\section{Perspectives on motivation}

Students' interests, attitudes and opinions about themselves express the degree of motivation and involvement in the learning activity. Bloom (quoted by Friedrich, 1982) identified four areas related to motivation:

- affects the subject: it materializes in the student's interest for a certain field.

- affects school: outlines different attitudes towards school and learning.

- the concept of academic self: the student finds himself in the relationship with school and learning.

- unitary interest: learning efficiency and success is a kind of learning task that involves interest and motivation for a new task and to address new learning topics.

It shouldn't be surprising that motivation influences the desire to engage in learning tasks. For example, teens spend a lot of time communicating via email or messenger or talking to friends on the phone. Trying to get the same interest from young people to read a novel or learn a foreign language can be a difficult attempt. Next, we will examine some of the contemporary perspectives on motivation in modern education.

The interests of the students. Hidi and Harackiewicz (2000) examined possible connections between students and motivation. Interest has been conceptualized as the interactive relationship between individuals and certain aspects of their environment. Some people are interested in social studies, some in art, others in sports. Interest can be understood as a state or disposition of the 
individual and can be characterized by cognitive and affective traits. Research suggests that interest plays an important role in academic performance. It is obvious that students will follow more closely and will put more effort into the areas that interest them.

Individual and situational interest. In current theories of motivation, researchers differentiate between two types of interests: individual and situational interest. The first refers to stable dispositions that develop over time, in relation to a particular subject or a certain general theme. Therefore, a student may develop an interest in history that will last throughout his or her educational experience. We mention, however, that the specificity of certain circumstances created by the teacher-student relationship or by the relationship between the presented topic and the student's interests can influence the degree of attraction towards the respective field. Thus, the interest promoted in this context may or may not last. For example, a dramatic lecture or a unique experiential activity can activate students' interest in a topic previously considered boring. The oratorical talent, the pedagogical tact of the teacher influences to a great extent the preservation of the interest for a certain intellectual preoccupation of the student. Hidi and Harackiewicz (2000) noted that individual and situational interests may be distinct, but not contradictory. Individual interest can serve as a filter for situational interest, while situational interest can fuel individual interest. The authors believe that individual interest in a particular topic can help students to persevere and progress through seemingly boring presentations or reading texts on a specific topic; situational interest, being achieved through such presentations or readings, can maintain motivation and performance even when the individual has no personal interest in certain areas or topics. Interest is also related to intrinsic motivation. This is defined as the motivation to engage in activities for their own sake (Hidi \& Harackiewicz, 2000, p. 155). The definition includes both individual and situational interest. Some students may "sip" Harry Potter novels because they are prone to reading. Interest in reading can also be promoted for situational reasons. When the teacher assigns a student the task of presenting Harry Potter novels to the class, he will become extremely interested and will read the whole series breathlessly. It is simplistic to visualize motivation in terms of either/or. Specifically, students are not intrinsically or extrinsically motivated in all circumstances. Students can be intrinsically motivated in some subjects and extrinsically motivated in others. Some students may be very interested in literature, but they need an external reward to study mathematics. Similarly, some students may listen carefully to an academic lecture but will have performance goals in other areas that concern them much more.

\section{Teacher-student communication}

In the following section we will discuss the third component of the learning model, explained by Friedrich (1982) - the quality of teacher-student communication. The effects of classroom communication are circular, and their impact on learning is difficult to determine. In addition, differences in contexts and methodological variations used to study communication make comparisons 
problematic. Powell, G. R. \& Caseau, D. (2004) characterized classroom action as a game of rules that teachers and students follow. Thus, there are used four ways of communication:

1. Structuring moves are used to establish the context of appropriate student behavior. Teachers might say, "Today we're going to discuss the reading topic we did yesterday." The teacher's requests actually imply a verbal response from the students.

2. The response actions follow the request actions. They consist of replies to the students' answers.

3. Reaction moves are statements used to change or evaluate what students have said. When classroom communication is defined in this way, the teacher is expected to contribute most of the discussion. In most classrooms, teachers talk about $70 \%$ of the time.

Haslett (1987) argued that instructional communication involves three linguistic functions. One of the functions involves leading /coordinating the students. This type of communication is concerned with providing students with the information they need to complete a training task. A second function, informative, involves students' access to new informational content. The third linguistic function involves and provokes students' answers. For example, asking students if they understand a particular task is a way to challenge. Teachers' questions are therefore one of the main forms of communication used in the classroom. Research suggests that teachers need to engage in a limited range of behaviors. They provide information, ask for information and directly observe the student's behavior. These descriptions, although informative, do not provide an insight into the effects of these communication models on students' learning and academic achievement. Research shows that the use of questions in discussions, associated with the clarity of teacher presentation have an important impact on learning (Brophy \& Good, 2000).

Questions. Teachers use questions to solicit student participation and to involve them in the learning process. Brophy and Good (2000) pointed out that research conducted over 30 years shows that teachers' frequently asked questions correlate positively with students' results. However, the maximum effects on learning are related to the clarity of the question and how it is managed. Student outcomes are improved when teachers ask for clearly formulated answers, survey students' answers, redirect questions to nonparticipant students, wait for students' answers, and provide feedback on the accuracy of students' answers. Learning is not about the difficulty of the question. Teachers can ask a series of lower-level questions and then construct higher-level statements or questions. Asking only one type of cognitive question does not seem to promote learning.

Clarity. Learning is directly related to the clarity of teacher communication. It is facilitated when the teacher uses communication strategies to improve the understanding of the instructional material. Bush (1977) conceptualized the teacher's clarity in seven behaviors: (a) gives examples, (b) explains the task to be done, (c) gives written examples, (d) uses common examples, (e) provides explanations that the student understands, (f) speaks so that all students can hear; 
and (g) explains leisurely, without rushing. Aspects that negatively affect the clarity of communication include: ambiguity, vague style, coverage, bluffing, insufficient examples and "maze" language (speech stops, redundancy in expression etc.). Hines, Cruickshank, and Kennedy (1985) used factor analysis to identify the dimensions that underlie the clarity of teacher communication. They found that in this case, teachers explain important ideas and use extensive illustrations while explaining and providing various directions. They examined the clarity of teacher communication and its effects on learning efficiency and educational success. In this regard, three types of behaviors were examined: (a) the teacher emphasizes important aspects of the content, (b) explains the content using examples, (c) assesses and responds to perceived shortcomings in comprehension. The results obtained indicate that cognitive efficiency and educational success based on good instruction are positively correlated with the clarity of teacher communication.

After a systematic review of the literature, Brophy and Good (1986) stated that learning efficiency is maximized when teachers actively present materials, provide general classifications, provide summaries, and signal important key ideas. These communication strategies require teachers to use examples that can be correlated with students' individual and life experiences. The processing of information by students is done according to their own frames of reference and signals to the teacher the understanding or lack of understanding of the material presented. Finally, the clarity of the communication is the result of these negotiated processes. Think for a moment about the teacher who uses an example that students do not understand. According to research by Darling (1989), students usually report their lack of understanding in different ways.

\section{Avoiding communication}

Next, we will present the disadvantages of avoiding communication (AC) a behavior that limits classroom learning. Abstaining from or refusing to communicate is one of the most studied behaviors in the field of communication, but it has not been addressed or blamed too much in education. Hundreds of studies have been done, and the results are quite consistent. Regarding the educational context, they indicate that students who face communication avoidance have more difficulty in school work than students who have a low coefficient of communication avoidance. In summary, we can list some specific features of these students that avoid communication (cf. McCroskey \& McCroskey, 2002): they obtain smaller averages; does not ask for help from teachers; have problems articulating their personal training needs; have fewer peer friends; are less competent in communication; they do not feel competent in communicating with strangers; all of which can have detrimental effects on their academic performance.

Causes that lead to avoidance of communication. The data showing the negative effects of avoiding communication are quite consistent. However, there are some controversies about the causes that determine it. Daly and Friedrich (1981) stated that communication avoidance could be caused by genetics, skills 
acquisition, modeling, and consolidation.

- The genetic explanation proposes that avoiding communication can be related to factors such as sociability, physical appearance, body shape and skills related to motor skills. These predispositions are improved or negatively affected by environmental factors.

- Another way in which communication avoidance can occur is the way social skills are acquired. The studious student or the typical "nerd" may be the student who does not possess communication skills and cannot fit into the flow of social interaction. As a result, communication is not rewarded, and thus, the acquisition of new communication skills is stopped.

- The third explanation discussed by the authors is modeling. If the child is educated and surrounded by people who themselves avoid communication, the child will be modeled behaviorally in the same way.

According to Daly and Friedrich (1981), the most advanced theory for explaining communication is the theory of reinforcement (reward theory). An individual who receives a positive reinforcement for communication will not develop behaviors to avoid communication. A child who is told to be silent and not encouraged to communicate may develop negative attitudes toward communication. McCroskey and Richmond (1978) found that students in rural areas and small towns reported higher levels of communication avoidance than those in urban and middle-class communities. The authors argued that this finding "... is the first theoretically projected link between an environmental/mental factor and an empirically verified avoidance of communication". ${ }^{248}$

When comparing environmental factors that influence attitudes towards communication, children in urban areas face more communication requirements than children in rural areas. For example, rural students studied by McCroskey and Richmond (1978) attended small, homogeneous schools. A common and narrow set of competencies has led to poorer communication in these communities. Instead, urban students face a much wider set of communication constraints. As a result, they need to develop a wider range of skills to be successful. There has been a new approach in recent decades, which states that communication avoidance is determined by neurobiological factors and processes (Beatty, McCroskey, \& Valencic, 2001; McCroskey \& Beatty, 2000).

\section{Communication and cultural environment}

A specific element of communication is that it is based on cultural sources. Thus, the family environment, which carries the basic cultural values of society, should also be taken into account in the teacher-student communication process (Jones \& Jones, 1997, Berger, C. R. \& Burgoon M., 1995). Differences between family backgrounds refer to the belief system, economic conditions and social status. As a result, each student who comes from a certain family environment will perceive differently the values promoted by the school, as well as his relationship

248 McCroskey, J. C., \& Richmond, V. (1978). Community size as a predictor of development of communication apprehension: Replication and extension. Communication Monographs, 27, 212-219 
with teachers. What teachers need to do is take these differences into account during the communication process. They should perceive what the common areas between students are. If a common living area is large enough between two people, there will be more opportunities for communication between them. Therefore, for effective communication between individuals, the teacher should consider the concept of culture. Cultural harmony plays an important role in forming positive relationships between teachers and students. If individuals come from similar backgrounds, they can communicate more easily (Nader, 1993). Otherwise, communication becomes limited and more difficult and conflicts can arise. Teachers should take into account the cultural attributes of students in communication otherwise their authority may be weakened due to the resilience of some of the children. Teachers should be balanced in their approaches and behave according to students' cultural backgrounds (Celep, 2002). Teachers who know how to interact and communicate are able to analyze students, identify a common area from different cultures and make the teaching process more active and enjoyable.

\section{Conclusions}

To achieve his interaction with students, a teacher must be democratic, pleasant, patient, trusting and show a sense of humor. Probably, in order to become a teacher, it is necessary to somehow evaluate his interaction and communication performances, before recruiting. An effective learning-teaching process cannot work without good communication. Teachers, ultimately, should not only interact with students from different backgrounds, but also create a common area of communication in the classroom. This will also support universal culture. Over the years, researchers have come to appreciate the complexity of human communication. Early theoretical approaches were linear and simplistic. Contemporary orientations are complex and circular. Communication processes are negotiated between participants as they act on the meanings they construct and share. Verbal and nonverbal behaviors are the mechanisms by which the instructive meaning is achieved. Contemporary theorists also emphasize the strong relationship between learning and clarity of communication. Understanding instructional material is a direct consequence of how we communicate. We conclude by saying that understanding communication is an interesting and difficult challenge, on which researchers still have much to study.

\section{References}

1. Beatty, M., McCroskey, J. C., \& Valencic, K. (2001). The biology of communic ation: A communication biological perspective. Cresskill, NJ: Hampton

2. Berger, C. R. \& Burgoon M. (eds.), (1995). Communication and social influence processes. Michigan State University Press, East Lansing, MI

3. Brophy, J., \& Good, T. L. (2000). Looking in classrooms (8th ed.). New York: Harper \& Row 
4. Burgoon, J. K. (1985). Nonverbal signals. In M. L. Knapp \& G. R. Miller (Eds) Handbook of interpersonalcommunication (pp. 344390). Newbury Park, CA: Sage 5. Bush, A. (1977, April). An empirical investigation of teacher clarity. Paper pres ented at the annual meeting of the American Educational Research Association 6. Caliskan, N. \& Karadag, E. (2006).Attention, communication and confusing dim ensions in the period of learning-teaching. Cagdas Egitim Dergisi. 31 (331), 25-31 7. Celep, C. (2002). Classroom management and discipline. Ankara,Ani Publicati on

8. Collier, M. J., \& Powell, R. G. (1990). Ethnicity, instructional communication a nd classroom systems. Communication Quarterly, 38, 334-349

9. Darling, A. (1989). Signaling noncomprehensions in the classroom: Toward a d escriptive typology. Communication Education, 38, 34-40

10. Daly, J. A., \& Friedrich, G. (1981). The development of communication appre hension: A retrospective analysis of contributory correlates. Communication Quart erly, 29, 243-255

11. Demirel, O., Seferoglu, S. \& Yagci E. (2002). Teaching technologies and mate rial development. Ankara: Pegema

12. Friedrich, G. (1982). Classroom interaction. In L. Barker (Ed.), Communicatio $n$ in the classroom (pp. 55-76). Englewood Cliffs, NJ: Prentice-Hall

13. Goleman, D. (1997). Emotional intelligence. New York: Bantam Books

14. Gill, M. M. (1994). Accent and stereotypes: Their effect on perceptions of teac hers and lecture comprehension. Journal of Applied Communication Research, 22, 348-362

15. Haslet, B. (1987). Communication, strategic action in context. Hillsdale, NJ: L awrence Erlbaum Associates

16. Healy, J. M. (1998). Failure to connect. New York: Simon \& Schuster

17. Heather, C., Strawser, M. G. \& George, S. (1995). Communication Education and International Audiences: Reflections on Instructional Challenges and Pedagogical Strategy in Journal of International Students

18. Hewes, D. E. (ed.). (1995) The cognitive bases of interpersonal communication, Univ. of Minnesota, Lawrence Erlbaum Associates, Hillsdale, UK 19. Hidi, S., \& Harackiewicz, J. M. (2000). Motivating the academically unmotiva ted: A critical issue for the 21st century. Review of Educational Research, 70, 151 $-180$

20. Hines, C. V., Cruickshank, D. R., \& Kennedy, J. J. (1985). Teacher clarity and its relationship to studentachievement and satisfaction. American Educational Res earch Journal, 22, 87-99

21. Jones, V.F. \& Jones, L.S. (1997). Responsible classroom discipline: creating $p$ ositive learning environmentsandsolving problems. Boston: Allyn and Bacon Publi cation

22. Karadag, E. \& Caliskan, N. (2009). Interaction and Communication in the Process of Education and Shared Common Area in the Classroom. In College Student Journal. Vol. 43. 1, March, 2009. p. 123, Project Innovation, Gale Group 23. Knapp, M., \& Hall, J. A. (1992). Nonverbal communication in human interacti on (3rd ed.). San Diego: Holt, Rinehart \& Winston 
24. Lustig, M., \& Koester, J. (1999). Intercultural competence. Menlo Park, CA: Longman

25. Malcho, S. (2000). Body language. Giin Publication

26. McCroskey, J. C., \& McCroskey, L. L. (2002). Willingness to communicate an $\mathrm{d}$ communication apprehensionin the classroom. In J. L. Chesbro \& J. C. McCrosk ey (Eds.), Communication for teachers (pp. 19-34)

27. Allyn \& Bacon, Boston

28. McCroskey, J. C., \& Richmond, V. (1978). Community size as a predictor of d evelopment of communication apprehension: Replication and extension. Communi cation Monographs, 27, 212-219

29. Mehrabian, A. (1981). Silent messages (2nd ed.). Belmont, CA: Wadsworth 30. Mongeau, P. A., \& Blalock, J. (1994). Student evaluations of instructor immed iacy and sexually harassing behaviors:An experimental investigation. Journal of A pplied Communication Research, 22,256-272

31. Nader, J. (1993). Meeting the needs of multicultural classrooms, family valnes and the motivatien of minotity students, devesity and teacling: teacher education $y$ earbook. Texas: Jovanovich College Publications

32. Powell, G. R. \& Caseau, D. (2004). Classroom communication and diversity. Enhancing instructional practice. Fresno State University, Lawrence Erlbaum Associates, Mahwah, NJ

33. Rusu, Marinela (2015). Inteligenţa emoţională - Empatie şi comunicare interpersonală, Editura Universitas, Iaşi

34. Sanders, J. A., \& Wiseman, R. (1990). The effects of verbal and nonverbal tea cher immediacy onperceived cognitive, affective, and behavioral learning in the $\mathrm{m}$ ulticultural classroom. Communication Education, 39, 341-353

35. Yalin, H.I. (2001). Teaching technologies and material development. Ankara: Nobel Publication

36. Wolvin, A. D., \& Coakley, C. G. (1993). A listening typology. In D. Wolvin \& C. G. Coakley (Eds.),Perspectives on listening (pp. 15-22). Norwood, NJ: Ablex 